\title{
Adaptation to the digestion of non-starch polysaccharide in growing pigs fed on cereal or semi-purified basal diets
}

\author{
BY A. C. LONGLAND*, A. G. LOW, D. B. QUELCH AND S. P. BRAY \\ AFRC Institute for Grassland and Animal Production, Pig Division, Shinfield, Reading RG2 $9 A Q$, \\ Berks
}

(Received 1 September 1992 - Accepted 21 November 1992)

\begin{abstract}
Pigs (25-45 kg) were fed on either cereal or semi-purified basal diets supplemented with either high or low levels of sugar-beet pulp or wood cellulose (Solka-floc). The apparent digestibility and retention of $\mathrm{N}$ and apparent digestibility and metabolizability of energy (GE) and the apparent digestibility of nonstarch polysaccharides (NSP) and their constituent monomers were measured during weeks 2, 4 and 6 of the trial. $\mathrm{N}$ and GE were less well-digested, retained or metabolized from cereal basal diets than from the corresponding semi-purified diets during all three periods. NSP from sugar-beet pulp was highly digestible, unlike that from Soka-floc which was relatively poorly digested. These differences of NSP digestibility were seen more clearly when incorporated in semi-purified diets. There was no significant increase in the digestibility or retention of $\mathbf{N}$, or digestibility or metabolizability of GE, or in the digestibility of sugar-beet pulp NSP with increasing time-period on the diets. In contrast, the digestibility of Solka-floc NSP tended to increase with the time-period. The digestibility of NSP from the semipurified diet with the high level of Solka-floc inclusion was much lower than that for the low level of inclusion, indicating that microbial activity had been reduced. In conclusion, adaptation to the diets in terms of $N$ and GE balance may be complete after 1 week, but 3-5 weeks may be necessary before stability of measurements of the digestibility of resistant NSP monomers can be obtained.
\end{abstract}

Non-starch polysaccharides: Digestibility: Pigs

The capacity of micro-organisms in the intestines of pigs to ferment non-starch polysaccharides (NSP), mainly to volatile fatty acids, is well established and the literature on this topic was reviewed by Low (1985). It has also been demonstrated that the volatile fatty acids are rapidly absorbed and metabolized (Latymer \& Low, 1984, 1987) and that the total quantities may represent amounts which equal or exceed the maintenance energy requirements of the animal (Rérat et al. 1985; Longland \& Low, 1988, 1989). It is clear, however, from many studies that the extent of fermentation of NSP sources differs greatly. Accurate information on the relative extent of fermentation of different sources of NSP is important in relation to assessment of the nutritive value of foodstuffs with a high NSP content for pigs.

It is clear from studies in the rat (Walter et al. 1986) that the time-course of adaptation to diets with supplementary NSP may be up to 4 weeks (stool weight and bacterial mass) but caecal metabolic activity (volatile fatty acid, $\mathrm{H}_{2}$ and $\mathrm{CH}_{4}$ production) took longer. Systematic studies of this kind have not been done in pigs.

The extent to which microbial fermentation of NSP occurs depends in part on a sufficient supply of $\mathrm{N}$ for synthesis of microbial proteins. This supply could be small if the digestion

* Present address: AFRC Institute of Grassland and Environmental Research, Plas Gogerddan, Aberystwyth, Dyfed SY23 3EB. 
of dietary protein and of endogenous protein was virtually complete before the ileum and the large intestine, where most of the microbial activity occurs. From the point of view of assessing the fermentation of a specific NSP source it may help to use a diet which has no other NSP components, i.e. a semi-purified diet. However, such diets almost invariably contain highly digestible sources of protein (those with a low or intermediate apparent digestibility $(D)$ are generally associated with NSP and come from plant sources). Such a diet could, therefore, in theory, limit the amount of fermentation of NSP and, thus, lead to underestimation of the potential nutritive value of NSP-rich foodstuffs.

The aims of the present study in growing pigs were (a) to measure the development of NSP digestion and nutrient balance over $42 \mathrm{~d}$ and (b) to assess whether the amount of NSP fermentation was greater when the source was included in a basal diet with cereal components and soya-bean meal (which would not be fully digested in the small intestine) than when included in a semi-purified diet. Two NSP sources, wood cellulose and sugarbeet pulp, known to have low and high $D$ respectively (Longland \& Low, 1988) were compared, each at two levels of supplementation. The overall aim was to develop an in vivo system for evaluating different types of NSP as energy sources for pigs.

\section{MATERIALS AND METHODS \\ Pigs and housing}

Forty Large White $\times$ Landrace crossbred boars, initially of $25 \mathrm{~kg}$ live weight, were used. They were individually housed in a temperature-controlled building $\left(20 \pm 2^{\circ}\right)$, either in floor pens or metabolism cages arranged for separate collection of urine and faeces.

\section{Diets and feeding scales}

Eight diets were formulated to contain the same amounts of digestible energy and total lysine per $\mathrm{kg}$ : four were based on casein and starch (PPL, PSL, PPH, PSH) and four on wheat and soya-bean meal (CPL, CSL, CPH, CSH). Low (L) and high (H) levels of wood cellulose (Solka-floc; S; Brown \& Co., Berlin, NH, USA) or plain sugar-beet pulp (P) were used. Details are shown in Tables 1-3.

The feeding scales used were arranged so that all pigs received the same amount of basal diet at a given live weight. All scales were based on live weight. The two NSP sources were provided as supplements and they were included at either low or high levels. Diets were formulated so that the amount of supplementary NSP, rather than the total amount of the NSP source, was similar from the two sources at either the low or high inclusion level. The feeding levels relative to body weight per $d$ are shown in Table 1 for each diet.

The pigs were randomly allocated to the diets (five pigs/diet), and were fed daily at 08.30 and 15.00 hours. Water was mixed with air-dry diet immediately before feeding, at a level of $2.5 \mathrm{l} / \mathrm{kg}$. The pigs were weighed every $7 \mathrm{~d}$.

\section{Collection and sampling routine}

The pigs were weighed and placed in floor pens and given their experimental diets on day 0 of the trial. They were weighed again on day 7 and put into metabolism cages and from day 9 to day 14 all faeces and urine were collected. This cycle was repeated twice more until the end of the trial on day 42.

Urine was preserved with daily addition of $25 \mathrm{ml} 2.55 \mathrm{M}-\mathrm{H}_{2} \mathrm{SO}_{4}$. Faeces were collected twice daily and stored at $04^{\circ}$. Urine and faeces were weighed, mixed and sampled immediately after the collections ended. Samples were stored at $-20^{\circ}$ until they were lyophilized before analysis. 
Table 1. Composition ( $\mathrm{g} / \mathrm{kg}$ air-dry diet) and analysis of diets

\begin{tabular}{|c|c|c|c|c|}
\hline Semi-purified series $(\mathrm{P})$ & PSL & PPL & PSH & PPH \\
\hline Casein & $142 \cdot 5$ & $136 \cdot 7$ & $125 \cdot 9$ & $117 \cdot 1$ \\
\hline Starch & $685 \cdot 0$ & $657 \cdot 1$ & $604 \cdot 9$ & $562 \cdot 9$ \\
\hline Soya-bean oil & $2 \cdot 6$ & $2 \cdot 5$ & $2 \cdot 3$ & $2 \cdot 1$ \\
\hline Trace mineral mix* & $8 \cdot 7$ & $8 \cdot 3$ & 7.7 & $7 \cdot 1$ \\
\hline $\mathrm{NaCl}$ & $4 \cdot 3$ & $4 \cdot 2$ & $3 \cdot 8$ & $3 \cdot 6$ \\
\hline $\mathrm{CaHPO}_{4} \cdot \mathrm{H}_{2} \mathrm{O}$ & 17.9 & $17 \cdot 2$ & $15 \cdot 8$ & 14.7 \\
\hline $\mathrm{CaCO}_{3}$ & $4 \cdot 0$ & 3.9 & 3.5 & $3 \cdot 3$ \\
\hline Vitamin mix & $1 \cdot 7$ & 1.7 & 1.5 & 1.4 \\
\hline Choline hydrochloride & $1 \cdot 0$ & 0.9 & $0-9$ & 0.8 \\
\hline Solka-floc & $132 \cdot 3$ & - & 233.7 & - \\
\hline Sugar-beet pulp & - & 167.5 & - & $287 \cdot 0$ \\
\hline Feeding level $(\mathrm{g} / \mathrm{kg}$ body-wt per $\mathrm{d})$ & 27.9 & $29 \cdot 1$ & $31 \cdot 6$ & 33.9 \\
\hline \multicolumn{5}{|l|}{ Chemical composition } \\
\hline $\mathrm{N}(\mathrm{g} / \mathrm{kg})$ & $19 \cdot 1$ & $21 \cdot 2$ & 18.7 & 21.8 \\
\hline Gross energy $(\mathrm{MJ} / \mathrm{kg})$ & $15 \cdot 8$ & $15 \cdot 9$ & 15.9 & $15 \cdot 6$ \\
\hline Total NSP $(\mathrm{g} / \mathrm{kg})$ & $114 \cdot 0$ & $103 \cdot 0$ & $206 \cdot 0$ & 175.0 \\
\hline Cereal series $(\mathrm{C})$ & CSL & CPL & CSH & $\mathrm{CPH}$ \\
\hline Wheat & 681.6 & $685 \cdot 5$ & $614 \cdot 8$ & 578.5 \\
\hline Soya-bean meal & $178 \cdot 3$ & $172 \cdot 3$ & $160 \cdot 8$ & $151 \cdot 3$ \\
\hline $\mathrm{CaCO}_{3}$ & $13 \cdot 0$ & 12.6 & $11 \cdot 7$ & $11 \cdot 0$ \\
\hline $\mathrm{CaHPO}_{4} \cdot 2 \mathrm{H}_{2} \mathrm{O}$ & 10.5 & $10 \cdot 2$ & $9 \cdot 5$ & 8.9 \\
\hline $\mathrm{NaCl}$ & $4 \cdot 0$ & $3 \cdot 9$ & $3 \cdot 6$ & 3.4 \\
\hline Mineral and vitamin mix & $2 \cdot 2$ & $2 \cdot 2$ & $2 \cdot 0$ & 1.9 \\
\hline L-Lysine hydrochloride & 1.7 & $1 \cdot 6$ & 1.5 & 1.4 \\
\hline Solka-floc & $108 \cdot 7$ & - & $196 \cdot 1$ & - \\
\hline Sugar-beet pulp & - & $138 \cdot 7$ & - & 243.6 \\
\hline Feeding level $(\mathrm{g} / \mathrm{kg}$ body-wt per $\mathrm{d})$ & 33.9 & $35 \cdot 1$ & 37.6 & $40 \cdot 0$ \\
\hline \multicolumn{5}{|l|}{ Chemical composition } \\
\hline $\mathrm{N}(\mathrm{g} / \mathrm{kg})$ & $26 \cdot 6$ & $28 \cdot 1$ & $25 \cdot 9$ & $27 \cdot 0$ \\
\hline Gross energy $(\mathrm{MJ} / \mathrm{kg})$ & $15 \cdot 8$ & $15 \cdot 6$ & $15 \cdot 9$ & $15 \cdot 3$ \\
\hline Total NSP $(\mathrm{g} / \mathrm{kg})$ & $202 \cdot 0$ & $195 \cdot 0$ & $272 \cdot 0$ & $242 \cdot 0$ \\
\hline
\end{tabular}
(P).

PSL, PPL, PSH, PPH, CSL, CPL, CSH, CPH, high (H) and low (L) levels of Solka-floc (S) or sugar-beet pulp

* Trace mineral mix (g/kg): $\mathrm{K}_{2} \mathrm{CO}_{3} 447, \mathrm{MgCO}_{3} \cdot 3 \mathrm{H}_{2} \mathrm{O} 173, \mathrm{FeSO}_{4} \cdot 7 \mathrm{H}_{2} \mathrm{O} 33, \mathrm{MnSO}_{4} \cdot 4 \mathrm{H}_{2} \mathrm{O} 8, \mathrm{ZnCO}_{3} 10$, $\mathrm{NaF} 0 \cdot 8, \mathrm{CuSO}_{4} .5 \mathrm{H}_{2} \mathrm{O} 1 \cdot 75, \mathrm{COCl}_{2} 0 \cdot 6$, maize starch, $325 \cdot 85$.

\section{Chemical analysis}

$\mathrm{N}$ was measured by the Kjeldahl method and gross energy (GE) was measured by adiabatic bomb calorimetry. NSP was measured by the method of Englyst \& Cummings (1984). Dry matter and ash were determined according to standard AFRC Institute for Grassland and Animal Production procedures (Low et al. 1978).

$D$ values were calculated as:

\section{Digestibility measurements}

$$
D=\frac{I-F}{I}
$$

where $I$ is the amount of component eaten and $F$ the amount of component in the faeces.

Retention $(R)$ or metabolizability $(M)$ were determined as:

$$
R \text { or } M=\frac{I-(F+U)}{I}
$$


Table 2. Non-starch polysaccharide (NSP) composition of the experimental diets ( $g$ anhydrosugar/kg dry matter $(D M)$ )

\begin{tabular}{|c|c|c|c|c|c|c|c|}
\hline \multirow[b]{2}{*}{$\operatorname{Diet}^{*}$} & \multicolumn{7}{|c|}{ NSP constituents } \\
\hline & Arabinose & Xylose & Mannose & Galactose & Glucose & Uronic acids & Total NSP \\
\hline \multicolumn{8}{|c|}{ Semi-purified (P) series } \\
\hline PSL & $\operatorname{tr}$ & 12 & $\operatorname{tr}$ & $\operatorname{tr}$ & 116 & $\operatorname{tr}$ & 128 \\
\hline PPL & 32 & 1 & 1 & 7 & 34 & 42 & 117 \\
\hline $\mathrm{PSH}$ & $\operatorname{tr}$ & 21 & $\operatorname{tr}$ & $\operatorname{tr}$ & 208 & $\operatorname{tr}$ & 229 \\
\hline PPH & 55 & 2 & 1 & 12 & 58 & 72 & 200 \\
\hline \multicolumn{8}{|c|}{ Cereal (C) series } \\
\hline CSL & 20 & 46 & 2 & 11 & 139 & 9 & 227 \\
\hline CPL & 46 & 36 & 3 & 16 & 67 & 46 & 214 \\
\hline $\mathrm{CSH}$ & 18 & 50 & 2 & 11 & 212 & 9 & 302 \\
\hline $\mathrm{CPH}$ & 64 & 33 & 3 & 19 & 84 & 69 & 272 \\
\hline
\end{tabular}

tr, trace.

PSL, PPL, PSH, PPH, CSL, CPL, CSH, CPH, high (H) and low (L) levels of Solka-floc (S) or sugar-beet pulp (P).

* For details of diets, see Table 1 .

Table 3. Chemical composition of the non-starch polysaccharide (NSP) sources $(\mathrm{g} / \mathrm{kg}$ dry matter $(D M))$

\begin{tabular}{|c|c|c|c|c|}
\hline & \multicolumn{4}{|c|}{ NSP source } \\
\hline & Solka-floc & Sugar-beet pulp & Wheat & Soya-bean meal \\
\hline $\mathrm{DM}(\mathrm{g} / \mathrm{kg})$ & 935 & 923 & 894 & 879 \\
\hline $\mathrm{N}$ & 0 & 15.5 & $18 \cdot 0$ & $70 \cdot 0$ \\
\hline Oil & $2 \cdot 4$ & $16 \cdot 0$ & $25 \cdot 4$ & $31 \cdot 6$ \\
\hline Ash & 1.6 & $59 \cdot 4$ & $18 \cdot 6$ & $51 \cdot 0$ \\
\hline Lysine & $\operatorname{tr}$ & $5 \cdot 5$ & $3 \cdot 4$ & $27 \cdot 1$ \\
\hline Gross energy (MJ/kg DM) & $17 \cdot 3$ & $16 \cdot 3$ & $17 \cdot 9$ & $19 \cdot 3$ \\
\hline \multicolumn{5}{|c|}{ NSP constituents ( $\mathrm{g}$ anhydrosugar $/ \mathrm{kg}$ ) } \\
\hline Arabinose & $\operatorname{tr}$ & 178 & 21 & 21 \\
\hline Xylose & 86 & 7 & 44 & 13 \\
\hline Mannose & $\operatorname{tr}$ & 4 & $\operatorname{tr}$ & 10 \\
\hline Galactose & $\operatorname{tr}$ & 39 & 3 & 42 \\
\hline Glucose & 824 & 186 & 28 & 96 \\
\hline Uronic acids & tr & 231 & 4 & 30 \\
\hline Total NSP & 910 & 645 & 100 & 212 \\
\hline
\end{tabular}

tr, trace.

where $I$ is the amount of component eaten, $F$ the amount of component in faeces and $U$ the amount of component in urine.

\section{Statistical analysis}

All data were subjected to analysis of variance (Genstat, 1987). The main effects of basal diet (semi-purified $v$. cereal), source (sugar-beet pulp v. Solka-floc) and level of inclusion (low $v$. high) together with their interactions were tested for statistical significance. The analyses were performed within each time-period and were also averaged across the three balance periods. 
The three repeated measurements were summarized as linear and quadratic contrasts over time and analysed according to Rowell \& Walters (1976).

\section{RESULTS}

\section{Digestibility and retention of $N$}

$D$ and $R$ values for $\mathrm{N}$ from cereal-based diets were each significantly lower than those from their semi-purified counterparts (Table 4). High levels of NSP inclusion in the purified diets tended to result in a lower $D$ for $\mathrm{N}$, but no change in $R$ (Tables 4,7 ). The effect of reduced $D$ for N with high levels of NSP inclusion was less marked with cereal-based diets than that with the semi-purified diets. There was little evidence for changed $D$ or $R$ for $\mathrm{N}$ with increasing time-period on the diets (Table 4).

\section{Digestibility and metabolizability of energy}

The $D$ and $M$ values for energy from cereal-based diets were significantly lower than those from semi-purified diets (Tables 5, 7). High levels of Solka-floc (diets PSH and CSH) resulted in a substantial reduction in $D$ and $M$ for energy (compared with diets PSL and CSL). However, the levels of sugar-beet inclusion in cereal-based diets did not affect energy balance. When high levels of sugar-beet pulp were fed with a semi-purified basal diet (PPH) $D$ and $M$ for energy was slightly reduced $(P>0.05)$ relative to diet PPL. At similar levels of NSP inclusion, diets containing sugar-beet pulp had higher $D$ and $R$ for energy than the corresponding diets containing Solka-floc (Tables 5, 7).

The significance of the interactions between the three dietary factors are shown in Table 7, where there were significant two-way interactions between all factors and three-way interactions for $M$ for energy.

There was no evidence for enhanced use of energy with increasing time-period on the diets.

\section{Digestibility of NSP}

The $D$ values for NSP from diets containing sugar-beet pulp were significantly higher than those from diets containing Solka-floc (Table 6).

Higher $D$ values for NSP in all periods were seen for semi-purified compared with cereal basal diets in which sugar-beet pulp was the test NSP source. However, the converse was true for diets containing Solka-floc in periods 1 and 2, but not 3 .

The $D$ for NSP from sugar-beet pulp when it was the only NSP source (i.e. diets PPL and $\mathrm{PPH}$ ) was uniformly high and $\geqslant 0.95$ irrespective of its level of inclusion, at all time-points (Table 6). Similarly, the $D$ for arabinose, galactose, glucose and particularly uronic acids from these diets was high $(\geqslant 0.88)$. Xylose was less well digested from sugar-beet pulp than the other NSP constituents, but was still more extensively digested from sugar-beet pulp than from Solka-floc at the high levels of NSP inclusion.

The cereal-based diets containing sugar-beet pulp had lower total NSP $D$ values than the corresponding semi-purified diets and the total NSP $D$ for diet CPH was higher than that for diet CPL for all three balance periods. This demonstrates the highly digestible nature of most of the major NSP constituents of sugar-beet pulp in comparison to those of cereals.

Compared with sugar-beet pulp, Solka-floc NSP was relatively poorly digested especially when included at high levels in a semi-purified diet, when very little NSP (i.e. xylose and particularly glucose) was digested. However, there was some evidence of adaptation to these diets with increased exposure to them, as total NSP and glucose $D$ for diets PSL and PSH had improved (significantly and non-significantly respectively) by period 3 (Table 6).

Negative $D$ values were recorded for arabinose, mannose and galactose from diets PSL 
Table 4. Apparent digestibility and retention of nitrogen (expressed relative to $N$ intake) in balance periods 1, 2 and 3 for diets based on casein and starch (PPL, PSL, PSH and PPH) and wheat and soya-bean meal (CSL, CPL, CSH, CPH) at low $(L)$ and high $(H)$ levels of Solka-floc $(S)$ and sugar-beet pulp $(P)$ inclusion*

\begin{tabular}{|c|c|c|c|c|c|c|c|c|c|}
\hline \multirow[b]{2}{*}{ Diet } & \multirow[b]{2}{*}{ Balance period $\dagger \ldots$} & \multicolumn{4}{|c|}{$\mathrm{N}$ digestibility } & \multicolumn{4}{|c|}{$\mathrm{N}$ retention } \\
\hline & & 1 & 2 & 3 & Meant: & 1 & 2 & 3 & Mean $\ddagger$ \\
\hline \multicolumn{10}{|c|}{ Semi-purified (P) series } \\
\hline PSL & & 0.90 & 0.93 & 0.91 & 0.91 & 0.54 & 0.67 & $0 \cdot 68$ & 0.63 \\
\hline PPL & & 0.91 & 0.93 & 0.91 & 0.92 & 0.67 & 0.70 & 0.67 & 0.68 \\
\hline PSH & & 0.87 & 0.86 & 0.86 & 0.87 & 0.68 & 0.68 & 0.66 & 0.67 \\
\hline PPH & & 0.87 & 0.86 & $0-87$ & $0 \cdot 86$ & 0.72 & 0.72 & $0 \cdot 73$ & $0 \cdot 73$ \\
\hline \multicolumn{10}{|c|}{ Cereal (C) series } \\
\hline CSL & & $0 \cdot 76$ & 0.79 & 0.78 & $0 \cdot 78$ & 0.46 & $0 \cdot 50$ & 0.47 & 0.47 \\
\hline CPL & & 0.77 & $0 \cdot 79$ & $0 \cdot 82$ & $0 \cdot 79$ & 0.57 & 0.49 & $0 \cdot 51$ & $0 \cdot 50$ \\
\hline $\mathrm{CSH}$ & & 0.77 & 0.79 & 0.75 & 0.77 & 0.52 & 0.54 & 0.48 & 0.51 \\
\hline $\mathrm{CPH}$ & & 0.76 & $0 \cdot 76$ & $0 \cdot 75$ & 0.76 & 0.51 & 0.50 & 0.51 & 0.51 \\
\hline SEM & & 0.015 & $0 \cdot 018$ & 0.017 & 0.017 & 0.046 & 0.035 & 0.034 & 0.025 \\
\hline
\end{tabular}

* For details of diets, see Table 1.

$\dagger$ Periods 1,2 and 3 refer to weeks 2, 4 and 6 after pigs were first fed the diets.

$\ddagger$ Mean values for each diet over the three periods.

Table 5. Apparent digestibility and metabolizability of energy (expressed relative to gross energy intake) in balance periods 1,2 and 3 for diets based on casein and starch (PPL, PSL, $P S H, P P H)$ and wheat and soya-bean meal (CSL, CPL, CSH, CPH) at low (L) and high $(H)$ levels of Solka-floc $(S)$ or sugar-beet pulp $(P)$ inclusion*

\begin{tabular}{|c|c|c|c|c|c|c|c|c|c|}
\hline \multirow[b]{2}{*}{ Diet } & \multirow[b]{2}{*}{ Balance period $\dagger \ldots$} & \multicolumn{4}{|c|}{ Energy digestibility } & \multicolumn{4}{|c|}{ Energy metabolizability } \\
\hline & & 1 & 2 & 3 & Mean $\neq$ & 1 & 2 & 3 & Mean+ \\
\hline \multicolumn{10}{|c|}{ Semi-purified $(\mathrm{P})$ series } \\
\hline PSL & & 0.92 & 0.93 & 0.92 & 0.92 & 0.91 & 0.92 & $0 \cdot 91$ & 0.91 \\
\hline PPL & & 0.96 & 0.96 & 0.96 & 0.96 & 0.94 & $0-95$ & 0.95 & $0 \cdot 95$ \\
\hline PSH & & 0.79 & $0 \cdot 81$ & $0 \cdot 80$ & 0.80 & $0 \cdot 78$ & $0 \cdot 80$ & $0 \cdot 79$ & 0.79 \\
\hline PPH & & 0.94 & 0.94 & 0.93 & 0.94 & 0.93 & 0.93 & 0.92 & 0.92 \\
\hline \multicolumn{10}{|c|}{ Cereal (C) series } \\
\hline CSL & & $0 \cdot 80$ & $0 \cdot 82$ & 0.82 & 0.81 & $0 \cdot 79$ & $0 \cdot 80$ & 0.77 & $0 \cdot 79$ \\
\hline $\mathrm{CPL}$ & & 0.83 & 0.84 & 0.85 & 0.84 & $0 \cdot 81$ & 0.82 & 0.83 & 0.82 \\
\hline $\mathrm{CSH}$ & & 0.73 & 0.76 & 0.75 & 0.75 & 0.72 & 0.74 & 0.74 & 0.73 \\
\hline $\mathrm{CPH}$ & & 0.84 & 0.82 & 0.84 & 0.83 & $0 \cdot 81$ & $0 \cdot 81$ & $0 \cdot 82$ & 0.81 \\
\hline SEM & & 0.013 & 0.011 & 0.015 & 0.008 & 0.009 & 0.013 & 0.008 & 0.008 \\
\hline
\end{tabular}

* For details of diets, see Table 1.

† Periods 1, 2 and 3 refer to weeks 2, 4 and 6 after pigs were first fed the diets.

$\$$ Mean values for each diet over the three periods.

and PSH; it is important to note, however, that these sugars are present in these diets in trace amounts.

When Solka-floc was added to the cereal-based diet, $D$ for NSP from the diet with the high inclusion level (CSH) was again slightly, but not significantly, lower than that from diet CSL. $D$ values for NSP from diet CSH tended to be enhanced with increasing exposure to the diets (Tables 6 and 7). 


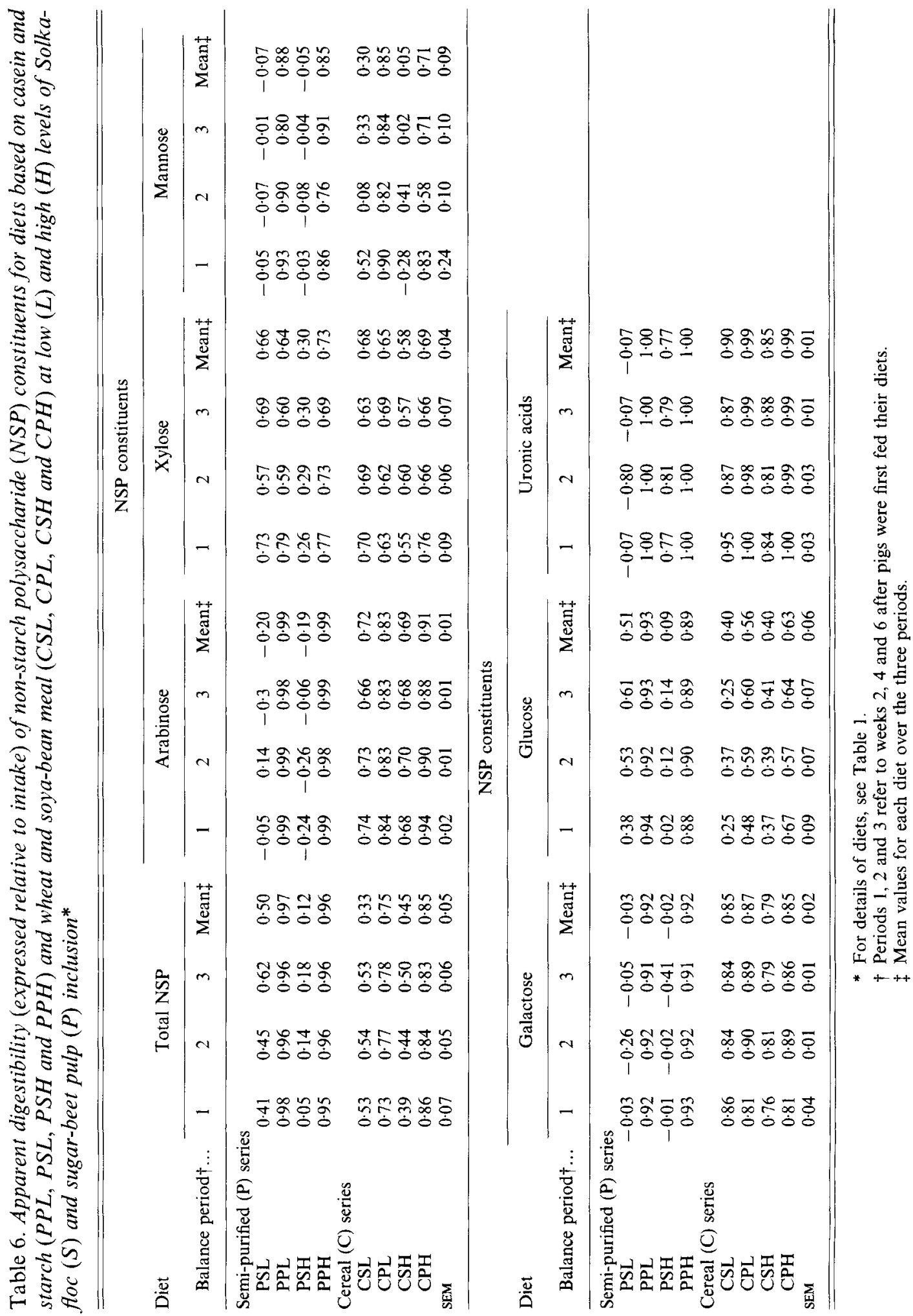


A. C. LONGLAND AND OTHERS

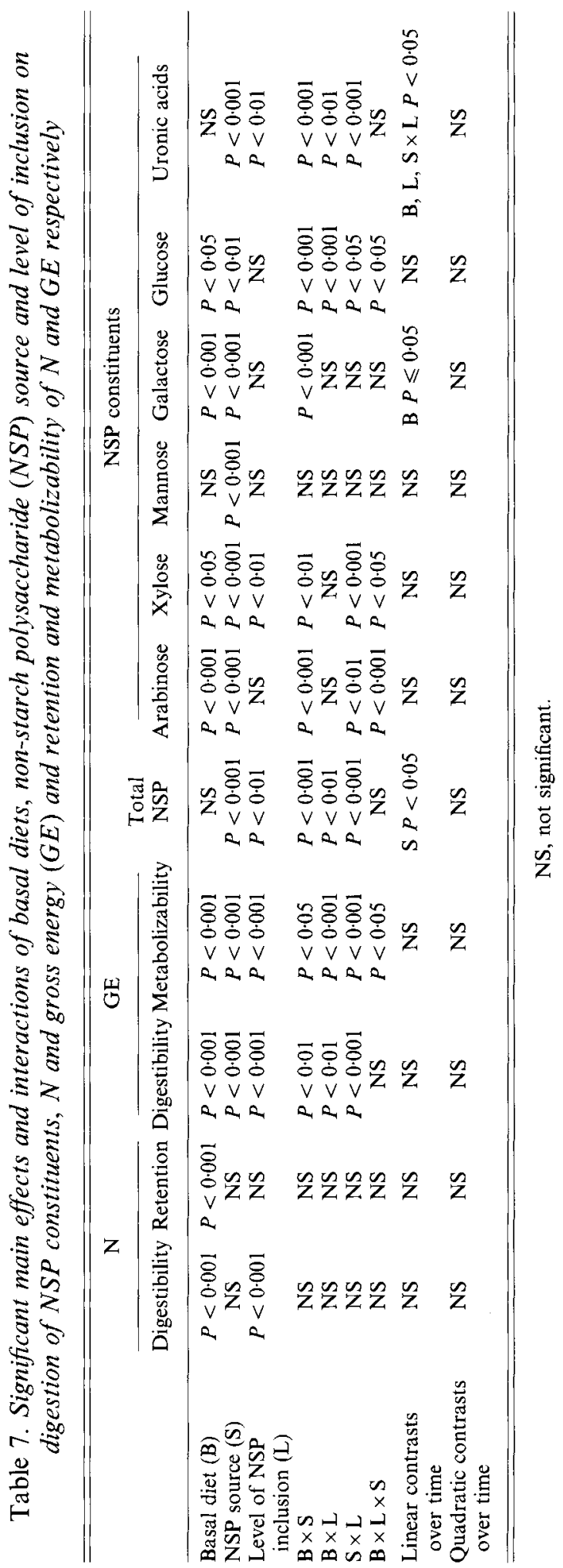




\section{DISCUSSION}

The $D$ and $M$ of energy by the pigs did not differ during the $42 \mathrm{~d}$ period. This shows that the gross effects of the sum of amylolytic digestion in the small intestine and of microbial activity were constant. Similarly, the apparent $D$ and $R$ for $\mathrm{N}$ remained constant, indicating that the gross effects of protease and peptidase activity in the stomach and small intestine remained constant. From these points of view steady-state conditions were achieved after a $7 \mathrm{~d}$ adaptation period to the diets. This is similar to the time allowed by many other workers for adaptation in growing pigs before $D$ measurements using diets without supplementary NSP.

The effect of increasing the supplementation of Solka-floc consistently reduced the $D$ and $M$ for energy, and this was also refiected in reduced $D$ for the NSP fraction. It seems that the capacity of the microflora to ferment Solka-floc is limited; in the case of the semipurified diets less by weight of the Solka-floc was fermented in diet PSH than PSL, implying that reduction of microbial activity occurred at the higher inclusion level. Depression of energy $D$ by Solka-floc (Partridge et al. 1983; Low et al. 1988) and by sugar-beet pulp (Longland et al. 1989) has also been seen in cereal-based diets. The effect of increasing the supplementation of NSP on $D$ for $\mathrm{N}$ from semi-purified diets tended to be negative but this was not always significant. Partridge et al. (1983) and Low et al. (1988) also observed this effect in pigs given cereal-based diets after supplementation with Solka-floc, and Longland \& Low (1989) found the same effect with cereal-based diets when supplemented at very high levels with sugar-beet pulp.

There were relatively few effects of time on NSP-component $D$, which is consistent with the absence of effects for $D$ for energy. The third collection from pigs given diets PSL and PSH yielded higher NSP $D$ values than the first collection, but this was not the case for diets containing sugar-beet pulp or for Solka-floc when included at low levels in a cereal-based diet. The increased $D$ for Solka-floc NSP over time may well indicate that adaptation of fermentation of Solka-floc takes several weeks, or, that the increased maturity of the animal enabled enhanced Solka-floc digestion. However, such a distinction is not important for the purposes of feed evaluation. The much higher $D$ for NSP from diets containing sugar-beet pulp than those containing Solka-floc is consistent with the results of Longland \& Low (1988). The $D$ for NSP from Solka-floc declined sharply at the higher inclusion level, corresponding with the fall in energy $D$ noted earlier, providing more direct evidence that ineffective microbial activity was responsible.

The values of $D$ for individual monomers in Solka-floc and sugar-beet pulp in the semipurified diet series correspond with those of Longland \& Low (1988), although in the latter the values for Solka-floc were rather higher, probably because of a lower inclusion level than in diet PSL. The values obtained in the cereal-diet series were similar to those found by Graham et al. (1986) and Longland \& Low (1988) in the case of diets supplemented with sugar-beet pulp at similar levels. The content of mannose and galactose is virtually zero in Solka-floc so the values for apparent $D$ are a reflection of endogenous or bacterial metabolism.

While there is a lack of information on the time-course of adaptation of the gut to changes in the dietary intake of NSP, the study in rats by Walter et al. (1986) is of interest. Measurements were made 4, 8 and 12 weeks after adult rats were given cereal-based diets supplemented with $100 \mathrm{~g}$ wheat bran or gum arabic/ $\mathrm{kg}$ (to give diets containing approximately 30 and $90 \mathrm{~g} \mathrm{NSP} / \mathrm{kg}$ respectively). Stool weight and bacterial mass were stable by 4 weeks, while $\mathrm{H}_{2}, \mathrm{CH}_{4}$ and volatile fatty acid output took longer to stabilize. This may be contrasted with the observation in growing pigs (W. H. Close, personal communication) that the reduction in heat output following the change from diets of low to 
high sugar-beet pulp and, hence, NSP content did not persist for more than $3 \mathrm{~d}$; at the same time a higher level of $\mathrm{CH}_{4}$ output was reached within $2 \mathrm{~d}$. Thus, some indicators of microbial and metabolic activity indicated that adaptation to a diet with high levels of certain sources of NSP is rapid. By contrast, Giusi-Perier et al. (1989) found that the extent of fermentation, as assessed by uptake of volatile fatty acids into the hepatic portal vein of pigs, increased up to 21-28 d following consumption of a high-cellulose diet. Such contrasting results may suggest an inverse relationship between the $D$ for an NSP source and the time of host and microbial adaptation to that NSP source.

We conclude that an adaptation period of only 1 week was sufficient for measurement of $\mathrm{N}$ and energy balance under the conditions of this trial, but a period of at least 3 weeks may be needed before stability of measurements of apparent $D$ for NSP monomers is established. It would appear important to assess NSP sources at more than one level of dietary inclusion, in view of the decreased fermentation of Solka-floc seen at the higher level of inclusion

The authors acknowledge with thanks statistical advice from Mr M. Dhanoa and financial support from the Department of Trade and Industry through its Biotechnology Scheme and from J. Bibby Agriculture Ltd, British Sugar plc, Dalgety Agriculture Ltd, Tate \& Lyle Research and Unilever Research.

\section{REFERENCES}

Englyst, H. N. \& Cummings, J. H. (1984). Simplified method for the measurement of total non-starch polysaccharides by gas-liquid chromatography of constituent sugars as alditol acetates. Analyst 9, 937-942.

Genstat (1987). Genstat 5 reference manual. Oxford: Clarendon Press.

Giusi-Perier, A., Fiszlewicz, M. \& Rérat, A. (1989). Influence of diet composition on intestinal volatile fatty acid and nutrient absorption in unanaesthetized pigs. Journal of Animal Science 67, 386 402.

Graham, H., Hesselman, K. \& Aman, P. (1986). The influence of wheat bran and sugar beet pulp on the digestibility of dietary components in a cereal-based pig diet. Journal of Nutrition 116, 242-251.

Latymer, E. A. \& Low, A. G. (1984). Tissue incorporation and excretion of ${ }^{14} \mathrm{C}$ in pigs after injection of sodium[U- $\left.{ }^{14} \mathrm{C}\right]$ acetate into the caecum. Proceedings of the Nutrition Society $43,12 \mathrm{~A}$.

Latymer, E. A. \& Low, A. G. (1987). Tissue incorporation and excretion of ${ }^{14} \mathrm{C}$ in pigs after injection of $\left[1-{ }^{14} \mathrm{C}\right]-$ or $\left[2-{ }^{14} \mathrm{C}\right]$ propionic acid into the caecum. Proceedings of the Nutrition Society 46, $113 \mathrm{~A}$.

Longland, A. C., Close, W. H. \& Low, A. G. (1989). The role of the large intestine in influencing the use of fibrous feeds by pigs. In Energy Metabolism of Farm Animals. Proceedings of the 11th Symposium, Lunteren, Netherlands. European Association of Animal Production Publication no. 43, pp. 111-114 [Y. van der Honing and W. H. Close, editors]. Wageningen: PUDOC.

Longland, A. C. \& Low, A. G. (1988). The digestion of three sources of dietary fibre by growing pigs. Proceedings of the Nutrition Society 47, 104A.

Longland, A. C. \& Low, A. G. (1989). Digestion of diets containing molassed or plain sugar-beet pulp by growing pigs. Animal Feed Science and Technology 23, 67-78.

Low, A. G. (1985). Role of dietary fibre in pig diets. In Recent Advances in Animal Nutrition-1985, pp. 87-112 [W. Haresign and D. J. A. Cole, editors]. London: Butterworths.

Low, A. G., Partridge, I. G. \& Sambrook, I. E. (1978). Studies in digestion and absorption in the intestines of growing pigs. 2. Measurements of the flow of dry matter, ash and water. British Journal of Nutrition 39, 515-526.

Low, A. G., Partridge, I. G. \& Taylor, J. A. (1988). Effects of different types of supplementary non-starch polysaccharides on nitrogen and energy digestibility (ileal and overall) and retention in pigs. Wissenschaftliche Zeitschrift der Wilhelm-Pieck Universität Rostock 37, 98-99.

Partridge, I. G., Keal, H. D. \& Mitchell, K. G. (1983). The utilization of dietary cellulose by growing pigs. Animal Production 35, $209-214$.

Rérat, A., Fiszlewicz, M., Herpin, P., Vaugelade, P. \& Durand, A. (1985). Measure de l'apparition dans la veine porte des acides gras volatils formés au cours de la digestion chez le porc éveillé (Measurement of the appearance of volatile fatty acids in the portal vein during digestion in the conscious pig). Comptes Rendus de I Academie des Sciences, Paris 300, 467-470.

Rowell, J. G. \& Walters, R. E. (1976). Analysing data with repeated observations on each experimental unit. Journal of Agricultural Science Cambridge 87, 423-432.

Walter, D. J., Eastwood, M. A., Brydon, W. G. \& Elton, R. A. (1986). An experimental design to study colonic fibre fermentation in the rat: the duration of feeding. British Journal of Nutrition 55, 465-479. 